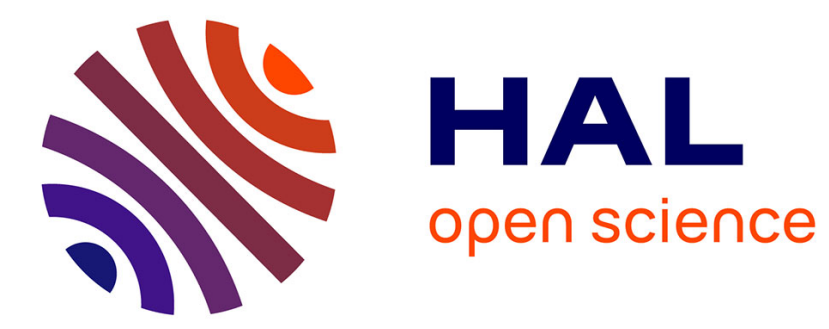

\title{
Thermal model of a dish/Stirling systems
}

\author{
François Nepveu, Alain Ferriere, Françoise Bataille
}

\section{To cite this version:}

François Nepveu, Alain Ferriere, Françoise Bataille. Thermal model of a dish/Stirling systems. Solar Energy, 2008, 83 (1), pp.81 - 89. 10.1016/j.solener.2008.07.008 . hal-03368331

\section{HAL Id: hal-03368331 \\ https://hal.science/hal-03368331}

Submitted on 7 Oct 2021

HAL is a multi-disciplinary open access archive for the deposit and dissemination of scientific research documents, whether they are published or not. The documents may come from teaching and research institutions in France or abroad, or from public or private research centers.
L'archive ouverte pluridisciplinaire HAL, est destinée au dépôt et à la diffusion de documents scientifiques de niveau recherche, publiés ou non, émanant des établissements d'enseignement et de recherche français ou étrangers, des laboratoires publics ou privés. 


\title{
Thermal model of a DISH/STIRLING system
}

\author{
François NEPVEU ${ }^{1 *}$, Alain FERRIERE ${ }^{1}$ Françoise BATAILLE $^{1}$ \\ ${ }^{1}$ CNRS-PROMES Laboratory, 7 rue du four solaire, 66120 Font-Romeu, France
}

\begin{abstract}
This paper presents a global thermal model of the energy conversion of the $10 \mathrm{~kW}_{\mathrm{el}}$ Eurodish Dish/Stirling unit erected at the CNRS-PROMES laboratory in Odeillo. Using optical measurements made by DLR, the losses by parabola reflectivity and spillage are calculated. A nodal method is used to calculate the heat losses in the cavity by conduction, convection, reflection and thermal radiation. $\mathrm{A}$ thermodynamic analysis of a SOLO Stirling 161 engine is made. The Stirling engine is divided in 32 control-volumes and equations of ideal gas, mass and energy conservation are written for each control-volume. The differential equation system is resolved by an iterative method developed using Matlab $^{\mathrm{TM}}$ programming environment. Temperature, mass, density of working gas, heat transfers and the mechanical power are calculated for one Stirling engine cycle of $40 \mathrm{~ms}$ and for a constant Direct Normal Irradiation (DNI). The model gives consistent results correctly fitting with experimental measurements.
\end{abstract}

\section{Keywords}

Eurodish, Dish/Stirling system, thermal model, heat losses, energy balance, Stirling engine

\section{Nomenclature}
Aw heat transfer area, $m^{2}$
$C_{p} \quad$ massic heat capacity at constant pressure, J. $\mathrm{kg}^{-1} \cdot \mathrm{K}^{-1}$
$C_{v} \quad$ volumic heat capacity at constant pressure, $J \cdot \mathrm{kg}^{-1} \cdot \mathrm{K}^{-1}$
$D \quad$ diameter, $m$
Diss thermal dissipation, $J$
DNI direct normal insolation, W. $m^{-2}$

\footnotetext{
* Corresponding author. Tel: +33 468307 714; Fax: +33 468302940.

E-mail address francois.nepveu@promes.cnrs.fr
} 
$k \quad$ thermal conductivity, $W \cdot K^{-1} \cdot m^{-1}$

$f \quad$ receiver tilt angle, rad

fr friction factor

$F \quad$ view factor

Gr Grashof number

$h \quad$ convective heat transfer coefficient, $W \cdot m^{-2} \cdot K^{1}$

$J \quad$ radiosity, $W \cdot m^{-2}$

$L \quad$ length, $m$

$m \quad$ working gas mass, $\mathrm{kg}$

$\dot{m} \quad$ mass flow, $\mathrm{kg} \cdot \mathrm{s}^{-1}$

$\bar{M} \quad$ molar mass, g.mo ${ }^{1}$

$n \quad$ number of regenerator screens or absorber tubes

$\mathrm{Nu} \quad$ Nusselt number

$P$ pressure, $\mathrm{Pa}$

$\delta Q \quad$ heat power in Stirling engine, $W$

$R \quad$ ideal gas constant, $\mathrm{J} \mathrm{Kg}^{-1} \cdot \mathrm{K}^{-1}$

Re Reynolds number

Rt thermal resistance, $K . W^{1}$

$S \quad$ area, $m^{2}$

$S_{\text {sec }}$ section area, $m^{2}$

$t \quad$ time, $s$

$T$ température, $K$

th thickness, $m$

$V \quad$ volume, $m^{3}$

$v \quad$ velocity, $\mathrm{m} . \mathrm{s}^{-1}$

$\delta W$ mechanical power, $W$

\section{Greek symbols}

$\pi_{T} \quad$ Stirling cycle period, $s$

$\varepsilon \quad$ total hemisherical emissivity

$\varphi \quad$ solar flux, W. $m^{-2}$ 
$\Theta \quad$ heat power in the receiver, $W$

$\triangle \mathrm{P} \quad$ pressure drop, $\mathrm{Pa}$

$\phi \quad$ phase angle, rad

$\sigma \quad$ Stefan - Boltzman constant, $W \cdot m^{-2} \cdot K^{4}$

$\lambda \quad$ wavelength, $\mu \mathrm{m}$

$\rho_{m} \quad$ mass density, $\mathrm{kg} \cdot \mathrm{m}^{-3}$

$\rho$ reflectivity

$\omega \quad$ angular speed, $\mathrm{rad} . \mathrm{s}^{-1}$

subscripts

a aperture

am ambient air

C compression control-volume

cav cavity

cer ceramic

d dead

inc inconel

E "expansion" control-volume

H absorber" control-volume

par parabola

sec section

w wall

exponents

Cd conduction

$C d v \quad$ conduction and convection

CV convection

$L T \quad$ low temperature, spectrum radiation emitted by a black body at a temperature about $1100 \mathrm{~K}$

rad thermal radiation

$S \quad$ solar spectral band $[\lambda<3 \mu m]$ 


\section{Introduction}

Since July 2004, a $10 \mathrm{~kW}_{\text {el }}$ Dish/Stirling unit is in operation at the CNRS-PROMES (French National Centre for Scientific Research) Laboratory in Odeillo in France. This system is one of the several Country Reference Units of the Envirodish project. It is a Eurodish system developed by ${ }^{\text {the }}$ Deutsches Zentrum für Luft und Raumfahrt (DLR) and Schlaich Bergermann und Partner (SBP) for solar electricity generation using a Stirling engine externally heated by concentrated solar radiation (Keck et al., 2006). During these two years, the system has accumulated 2500 operation hours and $14.6 \mathrm{MWh}_{\mathrm{el}}$ of electricity production with a power record of $11.1 \mathrm{~kW}_{\mathrm{el}}$ at $974 \mathrm{~W} / \mathrm{m}^{2}$ direct normal insolation, which corresponds to a net solar-to-electric efficiency of $21.6 \%$.

The present work is focused on the thermal modeling. The objective is to evaluate the optical and thermal losses of the system components, to identify the key parameters of the design and to study their influence on the performances of the components according to various operation conditions. The dynamic simulation of the system is also targeted in order to evaluate the efficiency on a daily, monthly or annual basis.

The thermal model is composed of a radiation transfer model for the cavity, which is coupled to the solar flux distribution, and on a thermodynamic model for the Stirling engine. The results are compared to experimental data issued from a campaign of optical and power measurements made by DLR in 2005 under a direct solar irradiation of $906 \mathrm{~W} / \mathrm{m}^{2}$ (Reinalter et al., 2006).

\section{Methodology}

The system is divided into five components, each of them representing a stage of the conversion cascade (figure 1). The optical losses of the concentrator (reflectivity, spillage) are determined using the distribution of solar flux density in planes close to the aperture (Reinalter et al. 2006). For a given direct solar irradiation, the thermal model of the cavity and of the absorber estimates the energy provided to the working gas of the Stirling engine and the heat losses by reflection, thermal radiation and convection. A nodal method is used to simulate one Stirling engine cycle, yielding the estimation of the generated mechanical power. The generator efficiency and the consumptions of all single components (water pump, tracking system, cooling fan) are user-defined inputs. 


\section{Optical and power measurements}

The effective parabola area considering the shadows is $52.9 \mathrm{~m}^{2}$ and the mirror reflectivity is measured at $92.5 \%$, a value somewhat lower than the design value (94\%). Reinalter et al. (2006) assessed the optical performance of the concentrator under elevated direct solar irradiation $\left(906 \mathrm{~W} / \mathrm{m}^{2}\right)$, using the flux mapping system developed by DLR and described by Ulmer et al. (2002). The solar receiver is composed of a ceramic cylindrical cavity $30 \mathrm{~cm}$ in diameter and $12 \mathrm{~cm}$ in depth, the concentrated solar radiation enters through an aperture of $19 \mathrm{~cm}$ in diameter. The cavity walls are insulated using a Silica-based ceramic material. The hexagonal absorber composed of 78 tubes made of Inconel of 3 $\mathrm{mm}$ outer diameter is placed at the bottom of the cavity.

Figure 2 shows the solar flux map in the focal plane normalized to $1000 \mathrm{~W} / \mathrm{m}^{2}$ of direct normal irradiation (DNI) and 94\% concentrator reflectivity. The aperture of the cavity is located in the focal plane, it has a diameter of $19 \mathrm{~cm}$ and it intercepts $85 \%$ of the incoming concentrated solar energy.

Figure 3 shows the solar flux distribution in the absorber plane, which is located $12 \mathrm{~cm}$ behind the aperture. It is observed that $78 \%$ of the concentrated solar energy directly hit the hexagonal absorber, while the remaining $7 \%$ hit the cavity wall. The flux distribution is rather inhomogeneous with a important peak of $1583 \mathrm{~kW} / \mathrm{m}^{2}$ and the mean solar flux on the absorber is measured at $702 \mathrm{~kW} / \mathrm{m}^{2}$.

\section{Receiver model}

A nodal method is used to calculate the heat losses by reflection, by thermal radiation and by convection out of the cavity, and by conduction trough the ceramic walls. The energy provided to the working gas flowing through the absorber tubes is also calculated over one complete cycle of the Stirling engine.

The receiver is divided into 11 control-volumes, named $\mathrm{i}=1$ to 11 :

-8 for the absorber ( $i=1$ to 8 ) to take into account the inhomogeneous flux distribution

-2 for the irradiated and shadowed ceramic cavity walls ( $i=9$ and $i=10$, respectively), -1 for the aperture $(i=11)$.

Each insolated control-volume ( 6 for the absorber, and 1 for the ceramic walls) is assumed to receive a uniform solar flux density calculated from flux map in the absorber plane (figure 3) and given in the 
table 1. The highest solar flux density of $1068 \mathrm{~kW} / \mathrm{m}^{2}$, a value lower than the flux peak of $1583 \mathrm{~kW} / \mathrm{m}^{2}$ is located on the "absorber" control-volume 5.

Figure 4 shows a cross-section of the receiver and Figure 5 the 8 control volumes of the absorber. Note that both control-volumes 1 and 8 are not insolated; they are hidden behind front tubes.

For each control-volume $\mathrm{i}$, the energy balance is written with one equation (Eq.1):

$$
\left(\rho_{m} C_{p} V\right)_{i} \frac{d T_{w_{i}}}{d t}=\sum_{j} \Theta_{j-i}+\Theta_{i}
$$

Where $\Theta_{j-i}$ is the heat transferred by conduction, convection or radiation from each control-volume j $(j=1$ to 11$)$ to the control-volume $i$, and $\Theta_{i}$ is the concentrated solar energy hitting the control volume i.

\subsection{Radiation transfer model}

The radiation transfers between the control-volumes are calculated using a radiation balance applied to the solar receiver. The spectrum of electromagnetic radiation is divided in two bands in order to take into account the spectral dependence of the optical properties of Inconel and Ceramic. The first one (S) corresponds to the solar radiation spectrum $(\lambda<3 \mu \mathrm{m})$ and the second one (LT) to the spectrum radiation emitted by a black body at a temperature about $1100 \mathrm{~K}(\lambda>3 \mu \mathrm{m})$. The optical properties of Inconel and Ceramic are given in table 2.

For these two spectral bands, the control-volume surfaces are assumed opaque diffuse and grey. The cavity aperture is considered as a black surface at ambient air temperature. The control-volume surfaces 1 and 8 are hidden and they do not participate in the radiation balance. For each controlvolume surface i, radiosities in the solar spectral band and in the LT spectral band are respectively given by equations (Eq.2) and (Eq.3). Total radiosity $\mathrm{J}_{\mathrm{i}}$, given by equation (Eq.5) is the energy flux leaving the surface i composed of emitted plus reflected energy. In the solar spectral band the radiosity $J_{i}^{S}$ is only composed of a reflected solar energy and in the LT spectral band the radiosity $J_{i}^{L T}$ is build from the emitted energy and the reflected LT energy by the other control-volume surface i. 


$$
\begin{aligned}
& J_{i}^{S}=\rho_{i}^{S} \cdot\left(\varphi_{i}+\sum_{j=1, j \neq 1, j \neq 8}^{11} F_{i j} J_{j}^{S}\right) \\
& J_{i}^{L T}=\mathcal{E} i \sigma T_{w_{i}}{ }^{4}+\rho_{i}^{L T} \cdot\left(\sum_{j=1, j \neq 1, j \neq 8}^{11} F_{i j} J_{j}^{L T}\right)
\end{aligned}
$$

The view factors $F_{i j}$ are computed by integration of differential equations for discrete areas issued from Siegel and Howell (1992).

Knowing the radiosity, equation (Eq.4) gives the net radiation balance $\Theta_{i}^{\text {rad }}$ for each control-volume:

$$
\Theta_{i}^{r a d}=S_{i}\left(J_{i}-\varphi_{i}-\sum_{j=1, j \neq 1, j \neq 8}^{11} F_{i j} J_{j}\right)
$$

Where $\mathrm{J}$ is the total radiosity of the surface $\mathrm{i}$ :

$$
J=J^{S}+J^{L T}
$$

The net radiation balance of the aperture, $\Theta_{11}^{\text {rad }}$, represents the receiver heat losses by reflection and by thermal radiation.

\subsection{Conductive and Convective heat losses in the cavity}

Some works in the literature provide correlations to calculate Nusselt number in a cavity as a function of the Grashof number Gr, receiver tilt angle $f$, aperture diameter $D_{a}$ and temperature walls $T_{w}$. The natural convective heat transfer coefficient $h_{\text {cav }}$ used in the receiver model is derivated from several correlations (McDonald, 1995). The Stine and Mc Donald correlation for the Nusselt number $\mathrm{Nu}$ is given as follows:

$$
N u=0.088 G r^{1 / 3}\left(\frac{T_{w}}{T_{a m}}\right)^{0.18}(\cos f)^{2.47}\left(\frac{D_{a}}{L_{c a v}}\right)^{s}
$$

And

$$
S=1.12-0.98\left(\frac{D_{a}}{L_{c a v}}\right)
$$

The natural convective heat losses $\Theta_{i}^{C v}$ through the aperture are given by equation (Eq.8): 


$$
\Theta_{i}^{C v}=\sum_{i \neq 11} h_{c a v} S_{i}\left(T_{w i}-T_{a m}\right)
$$

Where $h_{c a v}$ is derivated from Nusselt number:

$$
h_{c a v}=\frac{N u k a m}{L_{c a v}}
$$

The conductive heat losses $\Theta^{C d v}$ through the ceramic receiver walls and then evacuated to the ambient air by natural convection are calculated from thermal resistance $R t^{C d v}$. The ceramic thermal conductivity $k_{c e r}$ and the natural convective heat transfer coefficient $h_{a m}$ are assumed constant. The expression of conduction losses is given by:

$$
\Theta^{C d v}=\frac{\left(T_{w i}-T_{a m}\right)}{R t^{C d v}}
$$

Where for the control-volumes 9 and 10 :

$$
R t^{C d v}=\frac{1}{h_{a m} S_{i}}+\frac{1}{k_{c e r} 2 \pi L i} \operatorname{Ln}\left(\frac{D_{c a v}+2 t h_{c e r}}{D_{c a v}}\right)
$$

And for the control-volumes 1 to 8 :

$$
R t^{C d v}=\frac{1}{h_{a m} S_{i}}+\frac{t h_{c e r}}{k_{c e r} S_{i}}
$$

\subsection{Heat transfers in the absorber}

The flux density of solar distribution on the absorber tubes is inhomogeneous inducing temperature gradients and low heat transfers by conduction. Conductive heat transfers $\Theta_{j-i}^{C d}$ along the thin of the tubes between the 8 "absorber" control-volumes are calculated by equation (Eq.12).

$$
\Theta_{j-i}^{C d}=\frac{T_{w j}-T_{w i}}{R t_{j-i}^{C d}}
$$

Where

$$
R t_{j-i}^{C d}=\frac{L_{j}+L_{i}}{2} \cdot \frac{1}{k_{i n c} S_{\sec j-i}}
$$


And

$$
S_{\text {sec } j-i}=\frac{p i}{4}\left(D_{\text {outter }}^{2}-D_{\text {inner }}^{2}\right) \cdot n_{\text {tubesi }}
$$

\subsection{Receiver heat losses}

Finally, The energy balance for the aperture control-volume, 11, gives the total heat losses in the receiver.

$$
\Theta_{c a v}^{\text {losses }}= \begin{cases}-\Theta_{11}^{r a d} & \text { Reflection and IR emission losses } \\ +\sum_{j=1}^{10} \Theta_{j-11}^{C d v} & \text { Conduction losses through the ceramic cavity walls } \\ +\sum_{j=1}^{10} \Theta_{j-11}^{C v} & \text { Convection losses }\end{cases}
$$

\subsection{Absorber energy balance}

For the absorber control-volumes, equation (Eq.1) can be written as follows:

$$
\left(\rho_{m} C_{p} V\right)_{H i} \frac{d T_{w H i}}{d t}=-\Theta_{i}^{r a y}-\sum_{j}^{j \neq i} \Theta_{i-j}^{C d}-\Theta_{i-11}^{C d v}-\Theta_{i-11}^{C v}-\delta Q_{H i}
$$

Where $\delta Q_{H}$ is the energy provided to the Stirling engine, depending on the pressure, the temperature, the mass density and the velocity of the working gas.

\section{Stirling engine thermal model}

A Stirling cycle machine operates on a closed regenerative thermodynamic cycle using a working gas, and subjects the gas to expansion and compression processes at different temperatures. Since its invention by Robert Stirling in 1816 different engine configurations have been developed (Thombare, 2006). The EURODISH Stirling engine, SOLO 161 is of the alpha-type. Alpha-type engine have two pistons in separated cylinders arranged in " $\mathrm{V}$ ", which are connected in series by three exchangers: a heater (here a solar absorber), a regenerator and a cooler. 
Many works presents or uses thermal model more or less complex to approximate the real behaviour of the alpha-type Stirling engine. A review of these thermal models can be found in Dyson et al. (2004) and in Ercan et al. (2005).

For this study, a nodal analysis of the SOLO 161 is performed. The Stirling engine is divided in 32 control volumes as shown in figure 6 . The control volumes of compression $V_{C}$ and expansion $V_{E}$ spaces are variable and expressed by equation (Eq.17) and (Eq.18). The other control-volumes have fixed volumes.

$$
\begin{aligned}
& V_{E}(t)=\frac{V_{E}}{2}(\sin (\omega t)+1)+V_{E, d} \\
& V_{C}(t)=\frac{V_{C}}{2}(\sin (\omega t-\phi)+1)+V_{C, d}
\end{aligned}
$$

Mass equation (Eq.19), energy equation (Eq.20) and state equation (Eq.21) are written for each control-volume.

The following assumption are made in order to simplify the model equations:

1) The working gas is assumed to be an ideal gas

2) The total mass of the gas is constant within the Stirling engine

3) The instantaneous pressure is uniform

4) The compression and expansion spaces are adiabatic

5) The gas flow is one dimensional and quasi steady

$$
\begin{gathered}
\frac{d m_{i}}{d t}=\left(\dot{m}_{\text {in }}-\dot{m}_{\text {out }}\right)_{i} \\
\delta Q_{i}+\operatorname{DisS}_{i}+\left(C_{p_{(\text {Tin })}} T_{\text {in }} \dot{m}_{\text {in }}-C_{p_{(\text {Tout })}} T_{\text {out }} \dot{m}_{\text {out }}\right)_{i}+\delta W_{i}=C_{v\left(T_{i}\right)} \frac{d(m T)_{i}}{d t} \\
P V_{i}=m_{i} \frac{R}{\bar{M}} T_{i}
\end{gathered}
$$

In the control-volumes of the compression and expansion spaces, the mechanical power $\delta W_{i}$ is expressed by:

$$
\delta W_{i}=-P \frac{d V_{i}}{d t}
$$

And in the "heat exchanger" control volumes, the heat transfer $\delta Q_{i}$ is given by:

$$
\delta Q_{i}=h_{i} A w_{i}\left(T_{w i}-T_{i}\right)
$$


$h_{i}$ is the forced convective heat transfer coefficient calculated with two correlations. The classical Colburn correlation is used in the 8 "absorber" control-volumes and in the 10 "cooler" control-volumes. For the 10 "regenerator" control-volumes, the correlation given by Lemrani (1995) is used:

$$
N u_{i}=0.42 \mathrm{Re}_{i}^{0.56}
$$

Dissi is proportional to the pressure drop $\Delta P$ depending to the friction factor. As for the forced convective heat transfer coefficient, two correlations are used:

$$
\operatorname{DisS}_{i}=\Delta P_{i} \frac{P \bar{M}}{R T_{i}}\left(\frac{\dot{m}_{\text {in }}+\dot{m}_{\text {out }}}{2}\right)_{i}
$$

Where:

$$
\Delta P_{i}\left\{\begin{array} { c c } 
{ = f _ { r i } \frac { 1 } { 2 } \rho _ { m } v _ { i } ^ { 2 } n _ { i } } & { f _ { r i } = \frac { 3 3 . 6 } { \operatorname { R e } _ { i } } + 0 . 3 3 7 \text { For the "regenerator" control volumes } } \\
{ = f _ { r i } \frac { 1 } { 2 } \frac { \rho m v _ { i } ^ { 2 } L _ { i } } { D _ { i } } }
\end{array} \quad f _ { r i } \left\{\begin{array}{ll}
=\frac{64}{\operatorname{Re}_{i}} & \text { If } \mathrm{Re}_{i}<2000 \\
=0.316 \operatorname{Re}_{i}^{-0.25} & \text { If } \mathrm{Re}_{i}>2000
\end{array}\right.\right.
$$

\section{Numerical Resolution}

The differential equation system is resolved by an iterative method developed in Matlab. Temperature, mass, density of working gas, heat transfers and the mechanical power are calculated for one Stirling engine cycle of $40 \mathrm{~ms}$ and for a constant Direct Normal Irradiation. Periodic steady cyclic condition is obtained after few iteration cycles.

Mean value per cycle of the energy powers $G$ are the integration of the discrete powers $\delta G$ over the time and are calculated by equation (Eq.27):

$$
G=\frac{\int_{\text {cycle }} \delta G d t}{\pi_{T}}
$$

Few input data are necessary:

1) Geometric data of the receiver and Stirling engine. 
2) Working gas characteristics of the Stirling engine.

3) EURODISH operation data: engine speed, DNI, total working gas mass.

it is important to point out that EURODISH system regulates the total working gas mass and consequently the cycle mean pressure, to keep constant the maximal absorber temperature at $1053 \mathrm{~K}$. In the Stirling engine model, the total working gas mass is an input data and the absorber temperature is an output data. To solve this problem, a loop on the total working gas mass has been added in the numerical resolution in order to obtain a maximal absorber temperature of $1053 \mathrm{~K}$ over one Stirling cycle.

\section{Results and discussion}

Our numerical study is compared to experimental measurement given by Reinalter et al. (2006). The Eurodish operation data during the experimental measurements are provided in table 3 . Figure 7 gives the model results and the experimental measurements of the solar energy dispatching. The "numerical errors" designation is the difference between the energy input and output of the Eurodish system: For the experimental measurements this term is due to measurement errors (Reinalter et al., 2006) and for the model results, it includes errors coming from numerical integrations. Figure 7 shows the considerable energy losses in the receiver in particular by spillage. The losses by spillage, conduction, convection and radiation are estimated at $13.5 \mathrm{~kW}$, which represents $28 \%$ of the solar energy incoming of the dish. $31 \mathrm{~kW}$ is provided to hydrogen and $19 \mathrm{~kW}$ is evacuated to the cooler. The developed model gives good results in agreement with the measurements particularly in the receiver. The efficiency of the receiver defined as the proportion of the thermal energy introduced into the engine to the power that enters in the cavity is estimated at $81.4 \%$ and is measured at $82.6 \%$. The observed differences between the model results and the measurements are due to the Stirling model. The Stirling engine efficiency, which represents the conversion of thermal to mechanical power is calculated at $34.4 \%$ and is measured at $39.2 \%$. This difference can be explained by correlations used to calculate the forced convective heat transfer coefficients in particular in the regenerator where the gas flow is complex (Bonnet, 2005). Finally, the model finds a net solar-to-electric efficiency of $19.1 \%$ instead of $22.5 \%$, which gives a difference of $1.3 \mathrm{~kW}_{\mathrm{el}}$.

Figure 8 shows the absorber temperature distribution calculated by the model and measured by 20 thermocouples placed behind the absorber. The total hydrogen mass within the Stirling engine is 
adapted to obtain a maximal temperature about $1053 \mathrm{~K}$. This maximal temperature is located on the surfaces 4 and 5 . Figure 8 shows a good agreement between the model results and the measurements. The difference between the maximum and minimum temperature is calculated at $130 \mathrm{~K}$ when measurements gives about $100 \mathrm{~K}$. The temperature of the expansion space is estimated at $914 \mathrm{~K}$ and the cycle pressure at $115 \mathrm{Bar}$.

Figure 9 shows the power provided to the Stirling engine, the power provided to the cooler and the electrical power as a function of the DNI. The maximal absorber temperature is constant at $1053 \mathrm{~K}$. The model results are compared to experimental values of DNI, net electrical power and temperature in the cooler made automatically every second on the Eurodish system (Reinalter et al., 2006). The experimental net solar to electricity efficiency increases as a linear function of a DNI up to $800 \mathrm{~W} / \mathrm{m}^{2}$. When the insolation exceeds this level a blower in the receiver cavity is activated to reject additional heat and maintain the absorber at a fixed temperature of $1053 \mathrm{~K}$. Model give good results. For the electrical power the difference with experimental values is less than $1 \mathrm{~kW}_{\mathrm{el}}$ and is maximal at $700 \mathrm{~W} / \mathrm{m}^{2}$. At $800 \mathrm{~W} / \mathrm{m}^{2}$ the power provided to the cooler is evaluated at $16.5 \mathrm{~kW}$ and is measured at $17.5 \mathrm{~kW}$. This energy could be recuperated for a cogeneration application. In this case, the overall efficiency (Onovwiona et al. 2006) increases to $58 \%$. For the power provided to the Stirling engine It can be seen a constant difference of $1 \mathrm{~kW}$ between the model and the experimental values.

Figure 10 gives the energy dispatching calculated by the model for two DNI values: $400 \mathrm{~W} / \mathrm{m}^{2}$ and $800 \mathrm{~W} / \mathrm{m}^{2}$. The concentrator efficiency, defined as the proportion of energy entering in the cavity to solar energy intercepted by the dish is constant at $78.6 \%$. The losses by conduction, convection and reflection and thermal radiation in the receiver increase from $5.2 \mathrm{~kW}$ at $400 \mathrm{~W} / \mathrm{m}^{2}$ to $6.5 \mathrm{~kW}$ at 800 $\mathrm{W} / \mathrm{m}^{2} \mathrm{DNI}$, which gives a receiver efficiency of $72 \%$ and $80 \%$. The Stirling efficiency is constant at $34.4 \%$ and finally the net solar electricity efficiency drop from $800 \mathrm{~W} / \mathrm{m}^{2}$ to $400 \mathrm{~W} / \mathrm{m}^{2}$ due to the receiver efficiency decrease is $16.2 \%$.

\section{Conclusion and Perspectives}

This paper presented a thermal model of energy conversion of Eurodish Dish/Stirling. The model compared to experimental measurements gives good results and permits to study the detailed heat losses. Currently, the net conversion solar-electricity efficiency is about $21 \%$ at a DNI value of 
$900 \mathrm{~W} / \mathrm{m}^{2}$ and at an ambient temperature of $20^{\circ} \mathrm{C}$. The model shows important heat losses in the cavity by spillage and radiation (reflection and IR-emission) and consequently an improvement potential of system efficiency.

Future works will focus on the study of the influence of cavity physical parameters in order to design a new solar receiver. Using the ray-tracing code SOLTRACE and parabola slope error data, a parabola and receiver simulation are made to estimate and study the solar flux distribution in different planes. Then, theses flux maps will be introduced in the presented model. Furthermore, the model is used to evaluate energy provided to the cooler in order to test a Eurodish Dish/Stirling for a cogeneration application.

\section{Acknowledgements}

The authors wish to thank Isabelle VERDIER from CREED, Philippe LEFEVRE from R\&D EDF, Pascal STOUFFS from LATEP, Jean Michel GINESTE, Nicolas BOULLET and Emmanuel GUILLOT from PROMES, Wolfgang REINALTER, Steffen ULMER and Peter HELLER from DLR. 


\section{References}

Keck, T., Heller, P., Reinalter, W., 2006, Eurodish-continuous operation, system improvement and reference units, Proceeding of the $13^{\text {th }}$ SolarPACES international symposium, Seville, Spain Reinalter, W., Ulmer, S., Heller, P., Rauch, T., Gineste, J-M., Ferriere, A., Nepveu, F., 2006, Detailled performance analysis of the $10 \mathrm{~kW}$ CNRS-PROMES Dish/Stirling system, Proceeding of the $13^{\text {th }}$ SolarPACES international symposium, Seville, Spain

Ulmer, S., Reinalter, W., Heller, P., Lüpfert, E., Martínez, D., May 2002, Beam Characterization and Improvement with a Flux Mapping System for Dish Concentrators, Journal of solar energy engineering, 124-2, 182-188

Spiegel, R., Howell, J.R., 1992, Thermal radiation heat transfer, third edition, Taylor \& Francis

McDonald, C.G., 1995, Heat losses from an open cavity, College of engineering, California state polytechnic university, Pomona

Thombare, D.G., Verma, S.K., 2008, Technological development in the Stirling cycle engines, Renewable and Sustainable Energy Reviews, 12, 1-38

Dyson, R. W., Wilson, S.D., Tew, R.C., 2004, Review of computational Stirling analysis method, Proceeding of the $2^{\text {nd }}$ international conversion engineering conference, Providence, Rhode Island Ercan Ataer, O., Karabulut, H., 2005, Thermodynamical analysis of the V-type Stirling-cycle refrigerator, International journal of refrigeration, 28, 183-189

Lemrani, H., 1995, Modélisation énergétique des moteurs Stirling, Doctoral thesis, Ecole des mines de Nantes

Bonnet, S., 2005, Moteurs thermiques à apport de chaleur externe : étude d'un moteur STIRLING et d'un moteur ERICSSON, Doctoral thesis, Université de Pau et des pays de l'Adour

Onovwiona, H.I., Ugursal, V.I., 2006, Residential cogeneration systems: review of the current technology, Renewable and Sustainable Energy Reviews, 10, 389-431 
Table 1: Measured mean solar flux for each "absorber" control-volume

\begin{tabular}{|c|c|c|c|c|c|c|c|c|c|c|}
\hline Control-volume & & 1 & 2 & 3 & 4 & 5 & 6 & 7 & 8 & Absorber \\
\hline Mean Solar Flux & $\mathrm{kW} / \mathrm{m}^{2}$ & 0 & 501 & 403 & 1052 & 1068 & 569 & 521 & 0 & 702 \\
\hline
\end{tabular}

Table 2: Inconel and Ceramic properties

\begin{tabular}{|c|c|c|c|}
\hline & $\varepsilon$ & \multicolumn{2}{|c|}{$\rho$} \\
\hline & $1073 K$ & $\rho^{S}(\lambda<3 \mu \mathrm{m})$ & $\rho^{L T}(\lambda>3 \mu \mathrm{m})$ \\
\hline Inconel & 0.88 & 0.07 & 0.14 \\
\hline Ceramic & 0.9 & 0.15 & 0.12 \\
\hline
\end{tabular}

Table 3: Eurodish operation data

\begin{tabular}{|c|c|c|}
\hline working gas & \multicolumn{2}{|c|}{ hydrogen } \\
\hline $\mathrm{DNI}$ & $\mathrm{W} / \mathrm{m}^{2}$ & 906 \\
\hline $\mathrm{S}_{\mathrm{par}}$ & $\mathrm{m}^{2}$ & 52.9 \\
\hline Solar energy & $\mathrm{kW}$ & 48 \\
\hline $\mathrm{P}$ & $\mathrm{bar}$ & {$[130-140]$} \\
\hline $\mathrm{T}_{\mathrm{wH}} \max$ & $\mathrm{K}$ & 1053 \\
\hline $\mathrm{T}_{\mathrm{E}}$ & $\mathrm{K}$ & {$[903-923]$} \\
\hline$\left[\mathrm{T}_{\text {in }}-\mathrm{T}_{\text {out }}\right]$ water cooler & $\mathrm{K}$ & $295-305$ \\
\hline $\mathrm{T}_{\mathrm{am}}$ & $\mathrm{K}$ & 293 \\
\hline $\mathrm{Nt}$ & rt.min & 1500 \\
\hline
\end{tabular}




\section{Figure captions}

Figure 1: Model methodology

Figure 2: Solar flux map in the focal plane

Figure 3: Solar flux map in the absorber plane

Figure 4: Cross-section of the Eurodish receiver

Figure 5: Geometry and control volumes of the Eurodish absorber

Figure 6: Control-volumes in Stirling engine

Figure 7: Solar energy dispatching, Left: Model results, Right: experimental measurements (Reinalter et al. 2006)

Figure 8: Absorber temperature distribution: model results in underlined

Figure 9: Power provided to Stirling engine, power provided to the cooler and electrical power as function of DNI

Figure 10: Solar energy dispatching for two DNI values, Left: $800 \mathrm{~W} / \mathrm{m}^{2}$, Right: $400 \mathrm{~W} / \mathrm{m}^{2}$ 